American Journal of Environmental Sciences 4 (3): 204-211, 2008

ISSN 1553-345X

(C) 2008 Science Publications

\title{
An Applied Research Program on Water Desalination with Renewable Energies
}

\author{
${ }^{1}$ Sergio M. Alcocer and ${ }^{2}$ Gerardo Hiriart \\ ${ }^{1}$ Director, Instituto de Ingeniería, Universidad Nacional Autónoma de México, \\ Fernando Hiriart Bldg, 2nd Floor, Circuito Escolar, Ciudad Universitaria, México, DF 04510 \\ ${ }^{2}$ Researcher, Instituto de Ingeniería, Universidad Nacional Autónoma de México, \\ Torre de Ingeniería, 6th Floor, South Wing, Office 6, Circuito Escolar, Ciudad Universitaria, \\ México, DF 04510
}

\begin{abstract}
The use of renewable energy for desalination might be quite different in many places of the world. In Mexico, specifically in Baja California, there is an abundance of "traditional" renewable resources like sun and wind but also some others like hot springs at the coast, tidal currents and tidal amplitudes of over six meters in the upper part of the Gulf of California associated with a severe scarcity of fresh water. The National University of Mexico (UNAM) started two years ago a well organized research program to assess the amount of these resources and to find the way to use them for desalinating sea water. Very exiting results have being obtained: The abundance of hot springs at the shore, some of them over $84^{\circ} \mathrm{C}$, lead to the design of thermal desalinating prototype plants with very little energy consumption. It was found by geochemistry that at a few meters deep, some $50 \mathrm{~m}$, very high temperature can be obtained, easy to use in binary geothermal power plants to generate electricity for desalination. During the survey it was found that the amount of electrical power that can be generated with tidal storage and from deep sea hydrothermal vents is of the order of several thousands of MW. A special approach is also presented for the use of solar energy and the tidal currents of the Gulf. The IMPULSA research group at UNAM has been already consolidated with more than 30 students, dedicated to the design of appropriate equipment to make use of these resources and to characterize and quantify this huge amount of renewable energies that will permit to desalinate sea water.
\end{abstract}

Keywords: Gulf of California, solar energy, ocean energy, geothermal energy, turbine

\section{INTRODUCTION}

The northwestern part of Mexico is developing and growing very rapidly. This region's location, close to the border with the largest economy of the world, has encouraged an important industrial corridor, increasing water consumption in a zone where this resource is highly stressed and not available in large quantities.

Production of fresh water by desalination is becoming a major issue in the entire Peninsula, where people are willing to pay very high prices for this sought-after resource. Hundreds of small individual desalinating plants have been installed in most of the hotels and resorts of the area. All of them demand energy from the electrical grid extending from power plants in Rosarito, San Carlos or La Paz.

On the other hand, this region has being blessed with many renewable resources that can be used to desalinate water, as long as cost-effective and technically efficient ways to do it are developed.

Considerable work has been done around the world on using renewable energies for desalination ${ }^{[1],[2]}$.

However, in this project, the intention is to stress the identification of Mexican natural resources, and try to develop original techniques to solve Mexican particular problems.

Two years ago, the National Autonomous University of Mexico (UNAM) established the IMPULSA project, with three specifics goals:

1. To develop solutions to the scarcity of water in northwestern Mexico, considering the environment, costs and social impact of desalination. To this end, renewable energy resources were included in the conception of the project. The success of this goal must be measured by the amount of desalinating plants finally built -

Corresponding Author: Sergio M. Alcocer, Instituto de Ingenieria, Universidad Nacional Autónoma de México Fernando Hiriart Bldg, 2nd Floor, Circuito Escolar, Ciudad Universitaria, Mexico, DF 04510 Phone. +52.55 .5623 .3601$, Fax. +52.55.5623.3602 
whether by private or government developers with technology developed and transferred by UNAM

2. To form a solid group of engineers and researchers who would master the topics related to this project, and who would be able to transform science into applied solutions with a high degree of knowledge about renewable energies. This process would involve graduate students

3. And at the end of this process, knowledge and expertise must be disseminated to society via courses, books, seminars, on-site training, also transforming the involved groups at the Instituto de Ingeniería (Institute of Engineering) of UNAM into a consulting team.

Although the main topic of this project is the desalination of water using renewable energies, much other information has sprung up as a result.

\section{MATERIALS AND METHODS}

Behind all the IMPULSA projects there is a background and tradition in Mexico; previous work on renewable energies has served as a starting point. It is important to recognize that in geothermics for electricity we already have $956 \mathrm{MW}$ installed, making Mexico third place in world ranking. Similarly, at present we have more than a thousand people engaged in one way or another in geothermal exploration, drilling, reservoir evaluation and plant operation. Hence, on finding the hot spots in the Peninsula, many of the researchers involved in IMPULSA already had a good knowledge of the geological and physical properties of the territory. In particular, the co-author of this article worked for 26 years in developing geothermics in Mexico, ten of them as the General Manager for Geothermics. Regarding the solar possibilities, Mexico has done a lot of work with the World Bank to define the best place to install a hybrid solar Combined Cycle, with $25 \mathrm{MWe}$ with parabolic solar collectors, which is to be located in the northern part of the state of Sonora. As for the possibility of using tidal storage generation, the expertise of the CICESE in Baja California was well used with several discussions with the experts even though no specific reference was made to their work

The experience and background in renewable energy gave support in the shaping of this project and success up to the stage where we are now, trying to construct models for testing and prototypes to be installed in the real sites.
The IMPULSA Project at UNAM: The first step in launching this program was to find the appropriate people with a solid academic background, and to surround them with a group of graduate and undergraduate students form the core of the project. After that, ties with other well-known UNAM research programs that could provide technical help in specific areas were strengthened. The initial budget came completely from the University, with the expectation of sufficient external support after a few years.

In the beginning, effort was focused on training research personnel in desalination, asking them to use the governing basic equations to develop approximate solutions to a re-design of a broad range of desalination techniques. They were also asked to review the renewable resources available in the region. This effort involved many group discussions, field trips, and meetings with potential users and experts from other institutions. An external group of well- known authorities in the world on different subjects related with the project was appointed as an external advisory committee.

After a year of initial work, the initial list of topics was pared to only six lines of research. This selection was partially based on the research skills of the groups, and on the originality of the techniques to be used. In the near future we hope to enlarge the list of topics to include other areas of importance.

A permanent activity has been the improvement of the capabilities of the basic group of engineers, encouraging them to be well acquainted with the techniques of desalination and renewable energies, and updated with the most recent developments. Invited lecture and frequent site visits have been part of this training. Frequent group discussions of new ideas were encouraged, including the quantitative checks of feasibility from the very start.

The six lines of research selected were: 1. Hotwater desalination; 2. Geothermal electricity from lowenthalpy reservoirs; 3. Electricity from deep hydrothermal vents; 4. Electricity from tidal-storage hydro-generators; 5. Electricity from tidal-current turbines; and, 6. Solar photovoltaic intermittent desalination. In the remainder of this paper, these six projects are briefly discussed.

Hot-Water Desalination: During the survey along the coast of the Baja California Peninsula, many points with hot sea water were found (Fig. 1). Some are at the beach where the water is salty but very hot. The bestknown example is in Los Cabos, where an exploratory well was drilled to find a source of water for the 
desalinating plant planned for the zone. As soon as the water table was touched, a temperature of $85^{\circ} \mathrm{C}$ was found at 50 meters from the sea shore (Fig. 2). Because the membranes used for modern reverseosmosis technology do not withstand temperatures over $40^{\circ} \mathrm{C}$, the developers moved away from that hot spot and drilled a "normal" well several hundred meters away, where the temperature of the water was $26^{\circ} \mathrm{C}$. From the research point of view, to have sea water at $90^{\circ} \mathrm{C}$ is a real advantage for thermal desalination, because a temperature of $90^{\circ} \mathrm{C}$ at the water surface in a shallow well indicates the probability of temperatures around $150^{\circ} \mathrm{C}$ as one drills deeper.

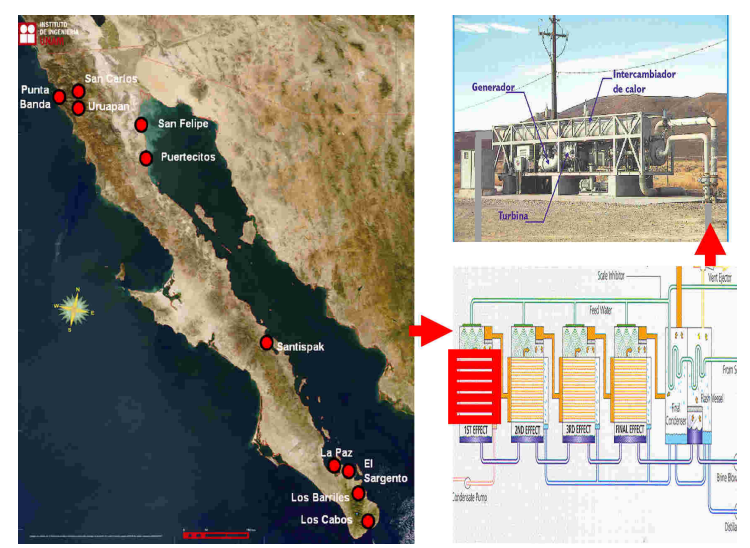

Fig. 1: Hot-water spots in the Gulf of California

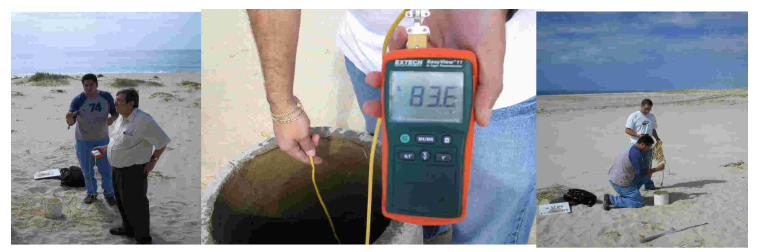

Fig.2: Measurements of hot-water wells in the Gulf of California

Researchers from the Institute of Geophysics at UNAM joined the IMPULSA project to perform a complete survey in the Peninsula. Using satellite imagery, hundreds of anomalous "hot spots", where large amounts of hot water reach the surface through geological fractures, have been identified. The information is corroborated by measuring the water temperature directly in the field, and obtaining samples of the water to determine is isotopic composition and better understand its origin.

Although some of these hot springs and wells are on-shore, many are under-sea, close to the coast at very shallow depths. The most important of these shallow, hot sea-water vents are near Puertecitos, Bahia
Conception and Ensenada. In those cases field measurements and sampling required some diving.

Based on current knowledge, each hot spring is different. Some have high amounts of dissolved gases; others have lower salinity than the surrounding sea water; others have high sulfur content.

This information is very valuable for the group in charge of designing the thermal desalinating equipment. To decide on an appropriate design, the availability and the quality of the hot sea water are very important. At the beginning, cases involving abundant hot water at $80^{\circ} \mathrm{C}$, with high gas content were considered. In this case the hot water was used in a heat exchanger to heat clean seawater and then to decrease the pressure to produce instantaneous evaporation in a multistage set of chambers. The innovation introduced in the design was the use of hot sea-water to heat all the chambers, not just the first one as in a conventional Multi-Stage Flash (MSF) plant. Because of that innovation, UNAM's design can be considered as a combination of MultiEffect Distillation (MED) and Multi-Stage Flash (MSF), and we have called it "Multi-Flash with Heaters" (MFWH). We are still in the stage of board design (Fig. 3).

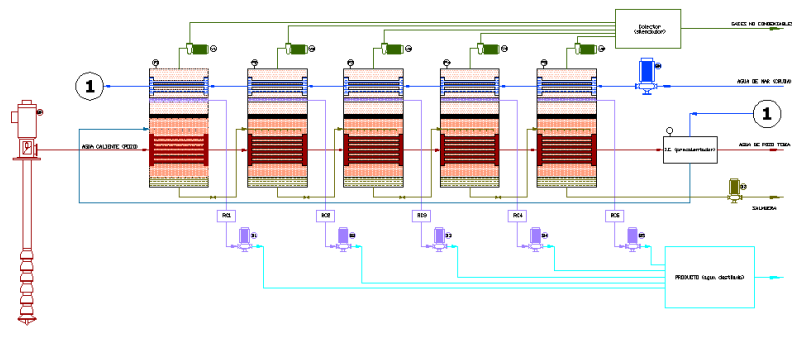

Fig. 3: "Multi-Flash with Heaters" (MFWH) IMPULSA's desalination plan

Our first model will soon be tested in the laboratory, followed by an on-site prototype. As soon as all problems related with basic thermodynamics and the pumping up of the hot sea-water are resolved, plan is to simplify the equipment and lower costs. The effect of different initial temperatures is being considered. Preliminary results indicate that for an initial temperature of $150^{\circ} \mathrm{C}, 4 \mathrm{~m}^{3}$ of sea water are required to produce $1 \mathrm{~m}^{3}$ of desalinated water. At an initial temperature of $80^{\circ} \mathrm{C}, 14 \mathrm{~m}^{3}$ are required. Several existing references address this topic ${ }^{[3]}$.

At this stage, the idea of the IMPULSA research team is to use its own equations and computer programs to design a desalinating plant as an issue of basic heat transfer and thermodynamics. Once the first model has been tested and the most important issues are identified, 
relevant experience of others will be carefully examined.

\section{Geothermal Electricity From Low-Enthalpy}

Reservoirs: Mexico has long experience in generating electricity from low-enthalpy geothermal resources, with a current installed capacity of almost 1000 $\mathrm{MWe}^{[4]}$. Almost all the available technologies for generation, from large condensing power plants of 110 MW down to small binary plants of $300 \mathrm{~kW}$ have been used. We are also aware of new developments in this field, especially those based on the binary cycle for low temperature resources, as like in Blumau, Austria and Alaska $^{[5]}$. According to our experience, roughly $140 \mathrm{t}$ per hour of hot water $\left(130^{\circ} \mathrm{C}\right)$ are needed to produce 1 MWe, which is enough to desalinate $250 \mathrm{~m}^{3}$ per hour.

With our existing information regarding geothermal possibilities in the Peninsula, we estimate that more than 50 MWe can be installed there, producing electricity for less than 5 US cents per $\mathrm{kWh}$. This price is quite competitive compared with the 10cent average that a private developer pays to the Government utility, and even more competitive compared with the rate of over 20 cents that is charged during peak hours (10 hours a day during the six summer months of the year).

At this point we are concentrating our efforts on geological, geophysical and geochemical surveys to identify the best place to drill a well, 2 to 3 hundred meters deep, and hopefully produce more than 150 tons per hour of hot seawater on the coast. If we find these conditions, the next step will be to install a commercial, binary-cycle generating plant and a commercial reverse-osmosis desalinating plant. The problem will then take on legal complications, because it is not common in Mexico for a private company to generate electricity and sell water.

Electricity From Deep-Sea Hydrothermal Vents: In some parts of the sea-bed under the Sea of Cortes, the continuous drift of the Baja California Peninsula to the northwest produces geological faults known as pullapart fractures, which permit magma to contact seawater, forming a kind of undersea volcano that ejects very hot jets of sea water through its crater Fig. 4. This phenomenon is quite rare, occurring only in the Galapagos Islands, in Juan de Fuca in front of Vancouver Island in Canada, and in some trenches in front of New Zealand. We know that Mexico has a large amount of such vents in the Sea of Cortes.
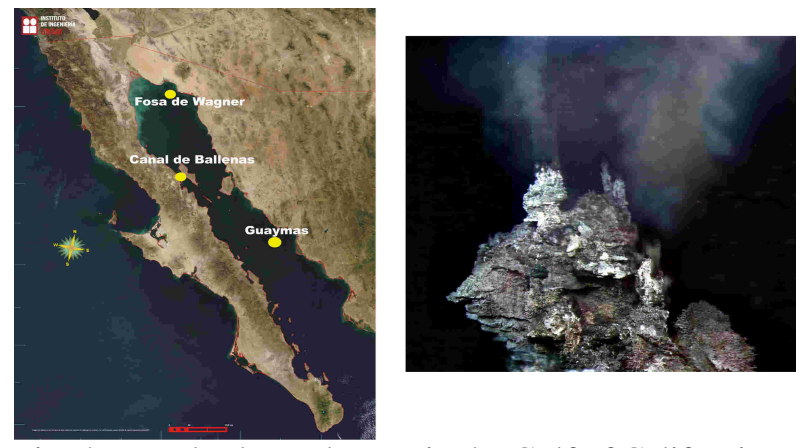

Fig. 4: Hydrothermal vents in the Gulf of California

On May 2007, the Wagner Trench in front of Puerto Peñasco was surveyed, where several vents have being reported ${ }^{[6],[7]}$. The survey was conducted using the Puma, UNAM's hydrographic nautical cruiser, and was led by researchers from the Institute of Geophysics and the Institute of Marine Sciences and Limnology. Geochemistry results are in process.

The IMPULSA team is also developing a submersible generator consisting of a heat exchanger, to be installed on top of the hydrothermal vent without touching it, thereby avoiding all interference with the benthic habitat of the sea floor (Fig.5). In this exchanger, a secondary fluid will be evaporated by natural convection, and in gaseous form will turn a steam turbine and generate electricity. A condenser located a few meters away from the vent will be installed to close the thermodynamic Rankine cycle. All this equipment will be encapsulated like a submarine in a water-tight tube, leaving outside the two heat exchangers (evaporator and condenser).

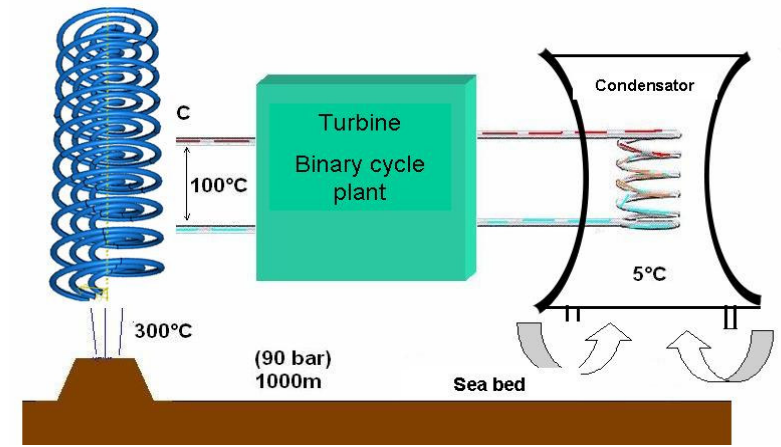

Fig. 5: IMPULSA's submersible generator

Preliminary calculations indicate that one can get up to $25 \mathrm{MWe}$ from one strong vent. Table 1 shows the electrical energy one could expect for different sizes and strengths of such thermal vents. 
Two heat exchangers to achieve maximum energy transfer without any external pumping are being designed. The evaporator is being developed as a multiple helical type, and the condenser as a hyperbolic, natural-draft cooling tower.

The first model will be tested in the laboratory, after which a bigger one, about $100 \mathrm{~kW}$ in capacity, will be built for on-site testing, probably in Bahía Concepción, a well-protected zone where vents are very shallow.

Electricity From Tidal Storage: In the upper part of the Sea of Cortes, the tide reaches amplitudes of 6 or more meters, because of the amplification from tidal resonance phenomena (Fig. 6). A tide of normal amplitude that reaches the entrance of the Gulf and travels at sea-wave surface velocity, arrives at the upper (northern) end of the Gulf, and returns in a time that is very similar to the tidal period of $12 \mathrm{~h}$. This produces a standing-wave phenomenon that leads to tremendous amplification of the tide at the upper end of the Gulf.

Also, tools for simulation of different alternatives have already been developed. Tests continue, with the most interesting one using an estuary, near Puerto Peñasco, where $80 \mathrm{MW}$ can be installed with very short dikes (Fig.7). This example shows that the technique of divided lakes can be used in many cases throughout the world, though perhaps not in the upper Gulf because of economics and environmental reasons.

Table 1: Expected electrical energy from different types of deepsea hydrothermal vents

\begin{tabular}{|c|c|c|c|c|c|}
\hline \multirow{4}{*}{$\begin{array}{l}\text { Electrical } \\
\text { Energy } \\
\text { MW }\end{array}$} & \multicolumn{2}{|c|}{$\begin{array}{c}\text { Inlet Temperature } \\
{\left[{ }^{\circ} \mathrm{C}\right]}\end{array}$} & \multicolumn{3}{|c|}{200} \\
\hline & \multicolumn{2}{|c|}{ Total Efficiency } & \multicolumn{3}{|c|}{18.62} \\
\hline & $\begin{array}{l}\text { Vent } \\
\text { Diameter } \\
{[\mathrm{cm}]}\end{array}$ & 25.4 & 50.8 & 76.2 & 101.6 \\
\hline & $\begin{array}{l}\text { Vent Area } \\
{[\mathrm{m} 2]}\end{array}$ & 0.05 & 0.2 & 0.45 & 0.81 \\
\hline \multirow{4}{*}{$\begin{array}{l}\text { Speed of } \\
\text { Flow } \\
{[\mathrm{m} / \mathrm{s}]}\end{array}$} & 0.2 & 0.63 & 2.53 & 5.69 & 10.12 \\
\hline & 0.5 & 1.58 & 6.32 & 14.23 & 25.2 \\
\hline & 1 & 3.16 & 12.65 & 28.46 & 50.59 \\
\hline & 2 & 6.32 & 25.29 & 56.91 & 101.1 \\
\hline
\end{tabular}

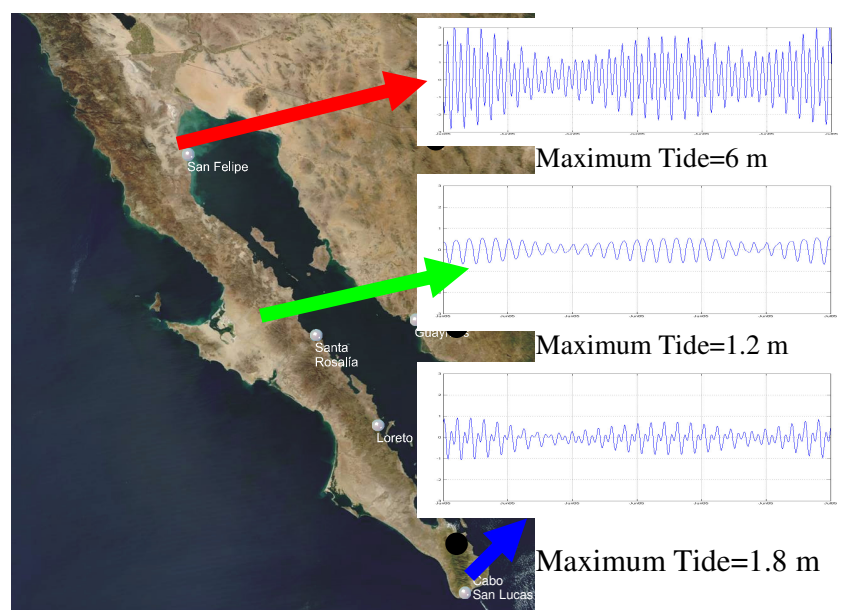

Fig. 6: Tidal resonance phenomena at the Gulf of California

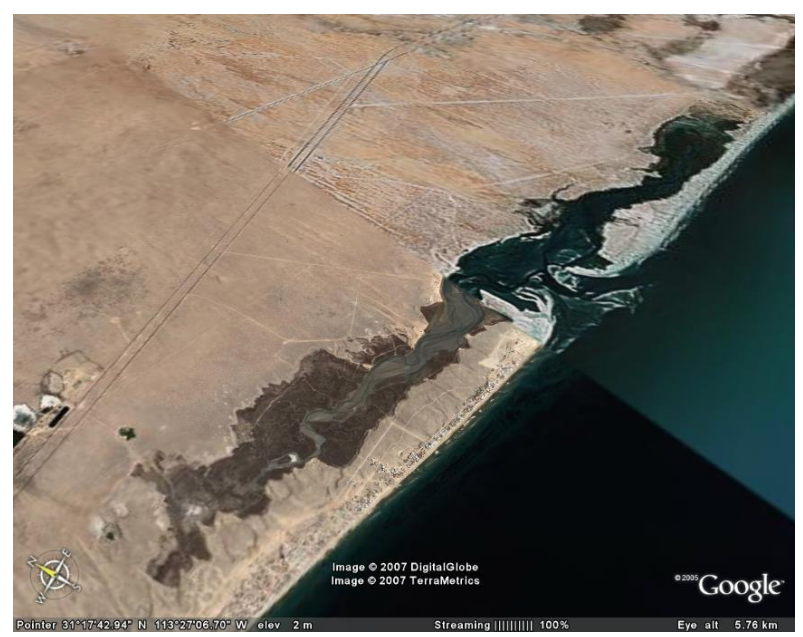

Fig. 7: Puerto Peñasco estuary

These days, a study is been made to determine the materials and methods of construction according to reasonable costs and an appropriate location in the upper Gulf, where tidal storage could be used.

Electricity From Tidal Currents: The movement of the sea entering and leaving the Gulf of California produces very intensive currents across the Gulf, especially in the channel between the two largest islands and the mainland. Currents of $3 \mathrm{~m} / \mathrm{s}$ or more are quite common. This observation led to the IMPULSA research group to design our own turbine to generate electricity in one of the channels (Fig. 8). 


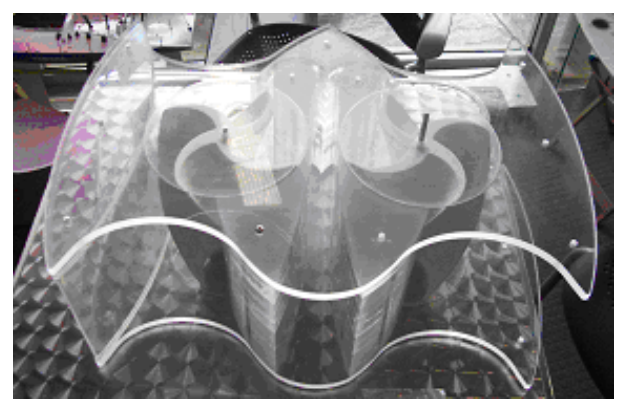

Fig. 8: IMPULSA`s turbine

A moored barge is equipped with two vertical halfcylinders, one on each side of the barge. Each halfcylinder has a vertically oriented propeller. Half of the propeller is always exposed to the running water of the tidal current and the other half is always hidden inside the half cylinder. The most important feature of this design is that the bow of the barge is built in order to conduct a stream of water through the inside of the boat turning it $180^{\circ}$ in order to hit, thought a nozzle the rear part of the hidden propeller (Fig. 9). To increase the flow rate and the velocity that will hit the barge, two floating devices are installed in the sides of the barge, in a curved form to produce a nozzle effect that will concentrate the water current in the active part of the turbine (Fig. 10).
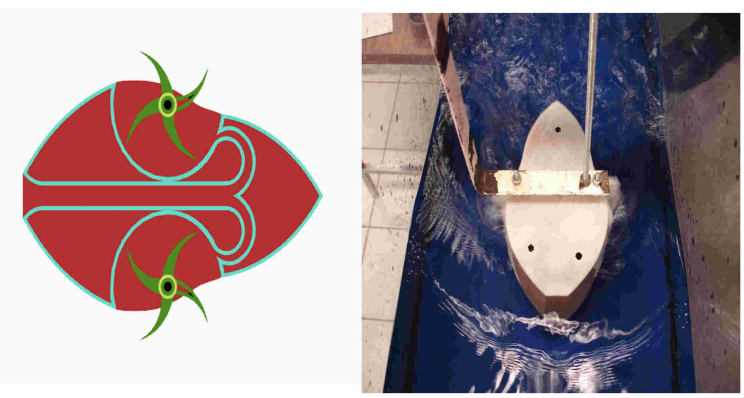

Fig. 9: Internal design of IMPULSA's turbine

At this point the model is to be tested at UNAM's laboratories in order to measure its efficiency and to make some modifications to improve it. After that, plans are to install a prototype with two generators of $25 \mathrm{~kW}$ each to be used in the Infiernillo Channel or in the Balsas River inland Mexico. A reverse-osmosis desalination plant is designed to be built on the deck of the barge, so that the whole barge can function as a mobile desalinating plant.

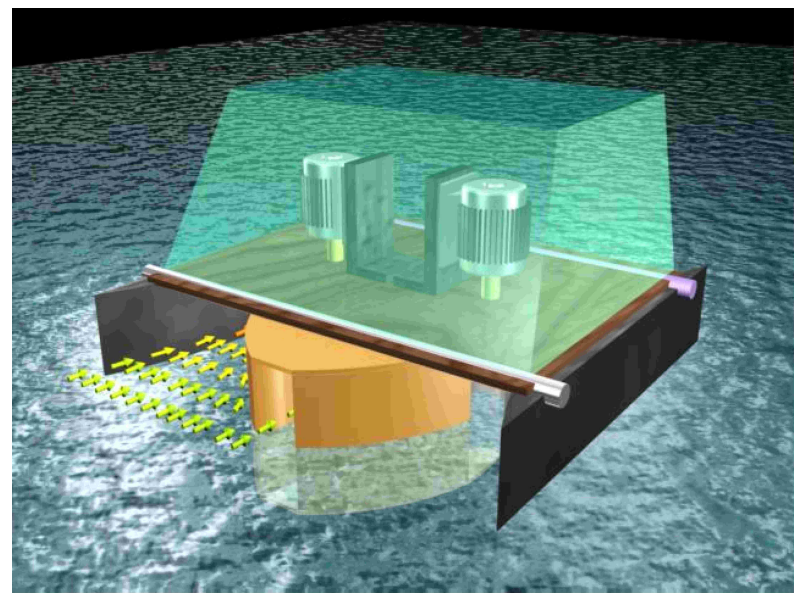

Fig. 10: Complete design of IMPULSA's turbine

\section{Solar Photovoltaic Intermittent Desalination Plant}

Baja California has excellent solar radiation, and its nice beaches and excellent weather have made it a site for luxury weekend homes. During weekdays, these houses are unoccupied, and water is needed to irrigate lawns and gardens. On weekends, the owners arrive, water demand increases. The idea of this project is to build small reverse-osmosis desalination plants, powered solely by solar radiation, and to run the necessary pumps with photovoltaic panels. The water desalinated during those 6-to- $8 \mathrm{~h}$ of radiation is pumped to an elevated tank using a solar-powered pump, for use either with automatic irrigation or as storage for the weekend. When the owners arrive on Saturday, the desalinating plant is connected to the electrical grid for continuous desalination. The solar panels are used only to save electricity during sunny hours ${ }^{[8]}$.

Our design is a desalination plant with a capacity of $8 \mathrm{~m}^{3}$ per day when running continuously, and $2 \mathrm{~m}^{3}$ per day when running on solar power only (Fig. 11). Our research is focused first on making the plant run with solar panels during sunny hours, starting in the morning and shutting off in the afternoon, but always desalinating at different rates depending on the level of solar radiation. The energy consumption required to start up the pumps is quite important, as is the variableload operation of the membranes. We are currently studing different ways of switching from work-week to weekend operation.

Although this part of the large project does not involve a high technical level of research, its main purpose is to use it as a first exercise of technology transfer from the IMPULSA research program to the end users, passing through the stages of marketing 
study, financing schemes, possible join ventures, among others.
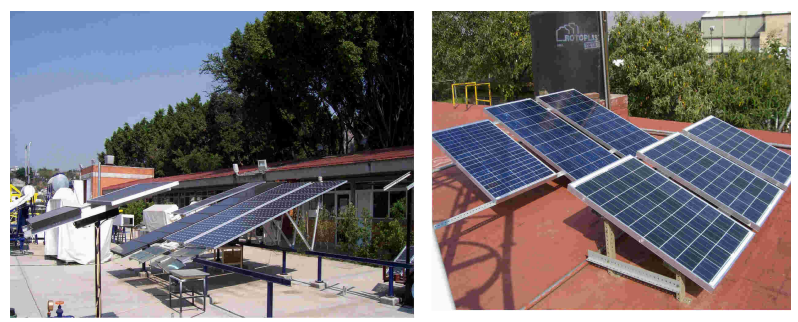

Fig. 11: Photovoltaic cells at UNAM's Solar Plant

\section{RESULTS}

As a result of the work described, it has been possible to organize and to train a solid group of researchers and students to find ways to desalinate sea water in Baja California with renewable energies. The group was lead by engineers and was composed of some 40 people, from several faculties of the university. The training was mainly based on technical visits to desalinating plants, on site measurements of the main parameters of the renewable resources and several lectures and personal assistance from very distinguished researchers from abroad who transmitted their experiences and offered steering suggestions for the project.

The identification of new renewable resources in the region was very important. It was found that the very high amplitude of the tides in the upper gulf, could produce many thousands of MW of electric power and, of course, for desalination. This result, theoretical at the beginning has been the threshold for further studies to locate smaller tidal barrages where the ecology is not affected and for other techniques, such as the two basin barrages where continuous generation can be obtained.

Theoretical calculations and some measurements at the site revealed the possibility of extracting energy from the tidal currents of the sea. A new concept model of an hydraulic floating turbine was designed and is presently being tested at the laboratory.

During the preliminary survey along the Peninsula, several hot spots of sea water where found. A more detailed campaign to achieve more precise measurements is under way. A piece of new desalinating equipment, called a Low Energy Multi Effect Distillation device (LE MED) was designed and is under construction for laboratory tests. Also the indirect geochemical identification of very high temperatures of underground water in many places on the coast was the incentive to begin studies to generate geothermal electric energy to run a desalinating plant. A scheme to extract heat for geothermal generation was initiated too.

A serious look at the possible use of the high temperatures involved in the hydrothermal vents of the California Gulf was given and a preliminary design for asubmarine generator, to be installed on top of the vents was made. If this new design works economically, it can produce thousands of MW

Finally, in the study of the possible use of solar energy in this well radiated region, it was decided to focus the research on the development of a small reverse osmosis plant, powered only by solar energy with photovoltaic panels, to be used in summer houses in the Peninsula and also plugged to the grid when needed, especially at weekends.

\section{DISCUSSION}

The belief that renewable energies are always expensive is widely held. Whilst that is true in many places, in this project it has been found that there are many special applications where renewable energy is not expensive and might be the best solution.

The work presented here is not a final solution, simply the identification of some niches which may become en extraordinary solution for the shortage of water in a very dry region.

The way to organize a research group based mainly on students and young engineers and having them trained with a strong component on field experience worked quite well. The inclusion of senior advisors, with qualified authority on the subject, was very useful.

\section{CONCLUSION}

After two years of work, the National Autonomous University of Mexico (UNAM) has put together a solid research and technology-transfer group on desalination processes, capable of participating in new feasibility studies and even trouble-shooting.

In the process of solving our own problems of desalination using the abundant sources of renewable energies available in Mexico, six research projects were undertaken: hot-water desalination; geothermal electricity from low-enthalpy reservoirs; electricity from deep hydrothermal vents; electricity from tidal storage hydro-generators; electricity from tidal-current turbines; and solar photovoltaic intermittent desalination.

At the present time, these six projects have advanced significantly. Perhaps the most important one, 
not yet finished, is the design of a hot-water desalinating plant. Also important is a small hydroturbine, working with tidal currents and installed on the side of a moored barge. Preliminary results indicate that this can provide a cost-effective and reliable turbine for electrical generation.

\section{ACKNOWLEDGMENT}

Authors are thankful for the financial support of the Universidad Nacional Autónoma de México. The contributions and technical assistance of the large group of researchers and students of the IMPULSA project is gratefully acknowledged.

\section{REFERENCES}

1. Belessiotis V., and E. Delyannis, 2001. Water shortage and renewable energies (RE) desalination possible technological applications. Desalination, 139 (1):133-138.

2. Tzen, E., and R. Morris, 2003. Renewable Energy Sources for Desalination. Solar Energy, 75 (5): 375-379.
3. Rodríguez-Girones, M.A., J. Pérez, and J. Veza, 1996. A Systematic Approach to Desalination Powered by Solar, Wind and Geothermal Energy Sources. Proceedings of the Mediterranean Conference on Renewable Energy Sources for Water Production, Santorini, Greece: 20-25.

4. Hiriart, G., and J. I. Andaluz, 2000. Strategies and Economics of Geothermal Power Development in Mexico. Proceedings of the World Geothermal Congress, Kyushu - Tohoku, Japan: 799-802.

5. Barbier, E., 2002. Geothermal Energy Technology and Current Status: An Overview. Renewable and Sustainable Energy Review, 6 (1-2): 3-65.

6. Tsurumi, M., and V. Tunnicliffe, 2003. TubewormAssociated Communities at Hydrothermal Vents on the Juan de Fuca Ridge, Northeast Pacific. Deep Sea Research, 50 (5): 611-629.

7. Tivey, M.K., A.M. Bradley, T.M. Joyce, D. Kadko, 2002. Insights into Tide-Related Variability at Seafloor Hydrothermal Vents from Time-Series Temperature Measurements. Earth and Planetary Science Letters, 202 (3 \& 4): 30 \& 693-707.

8. García-Rodríguez, L., 2003. Renewable Energy Applications in Desalination: State of the Art, Solar Energy, 5 (5): 381-393. 